\title{
Complexion of Boric Acid with 2-Deoxy-D-glucose (DG) as a novel boron carrier for BNCT
}

\author{
Zafer Akan ${ }^{1}$, Hasan Demiroglu ${ }^{2}$, Ugur Avcibasi ${ }^{2}$, Gokhan Oto ${ }^{3}$, Hulya Ozdemir ${ }^{3}$, Sabahattin Deniz ${ }^{4}$, Ali Sadi \\ Basak $^{5}$
}

\begin{abstract}
Objective: Boron neutron capture therapy (BNCT) is an intensive research area for cancer researchers. Especially the side effects and inabilities of conventional therapies in some cases, directs researchers to find out a new cancer therapy methods such as BNCT. One of three important problem of BNCT is targeting of boron to tumor tissue. Borono Phenyl Alanine (BPA) and Borono Sodium Borocaptate (BSH) are already using in clinical studies as boron carriers. New boron carriers are searching for high yield boron accumulation in the tumor tissue.

Methods: In this study, a novel ${ }^{10} \mathrm{~B}$ carrier was synthesized, $((2 R)-4,5,6$-trihydroxy-2(hydroxymethyl)tetrahydro-2H-pyran-3-yl)boronic acid $\left({ }^{10} \mathrm{~B}-\mathrm{DG}\right)$, for BNCT studies. ${ }^{10} \mathrm{Boric}$ Acid and 2Deoxy-d-Glucose was complexed $\left({ }^{10} \mathrm{~B}-\mathrm{DG}\right)$ through a low-high $\mathrm{pH}$ reaction and yield of complexion was tested with FTIR ATR and Liquid Chromatography Mass Spectrometry (LC/MS).

Results: Confirmation studies have been carried out by HPLC and chromatograms have confirmed that Borono-2-Deoxy-d-Glucose synthesized with $\% 80$ yield.

Conclusions: This compound appears to be an alternative boron carrier for BNCT applications

Keywords: ((2R)-4,5,6-trihydroxy-2-(hydroxymethyl)tetrahydro-2H-pyran-3-yl)boronic acid, 10B-DG, BDG BNCT, HPLC, FTIR-ATR, LC-MS
\end{abstract}

\section{Introduction}

Radiotherapy is a long-standing treatment method which makes use of ionizing radiation for the treatment of patients with malignancies. Ionizing radiations are absorbed by the all encountered tissues during radiotherapy. Side effects of ionizing radiation are unavoidable [1] Even different modalities and approaches are advancing the radiotherapy more radical changes such as BNCT are needed for patient life quality.

$$
\begin{aligned}
& { }^{10} \mathrm{~B}+{ }^{1} \mathrm{n} \rightarrow{ }^{7} \mathrm{Li}(0.84 \mathrm{MeV})+{ }^{4} \mathrm{He}(1.47 \mathrm{MeV})+\gamma(0.48 \\
& \mathrm{MeV}) 93.7 \% \\
& { }^{10} \mathrm{~B}+{ }^{1} \mathrm{n} \rightarrow{ }^{7} \mathrm{Li}(1.01 \mathrm{MeV})+{ }^{4} \mathrm{He}(1.78 \mathrm{MeV}) 6.3 \%
\end{aligned}
$$

The cornerstones of BNCT are the targeting of ${ }^{10}$ boron to tumor tissue (15-30 ppm), pure neutron radiation sources with high intensity $(\leq 10 \mathrm{KeV}$; $\approx 10^{9} \quad \mathrm{n}^{0} \quad \mathrm{sec} / \mathrm{cm}^{2}$ ) and simultaneously neutron radiation dose measurements during therapy.

Although development of different carriers such as monoclonal antibodiesdendrimers, liposomes, dextrans, polylysine, avidin, folic acid, and epidermal and vascular endothelial growth factors (EGF and VEGF), ideal alternative carriers are needed for BNCT application [2] As known, tumorigenic cells on mitosis process, needs constantly energy. Energy requirements are supplying from aerobic and anaerobic ways in the normal cells.

However in cancer cells oxygen supplies not enough due to delayed angiogenesis in the tumor tissue, there for, cells are compelled to supply ATP from anaerobic ways. In other words, required ATP is supplied by the glycolytic pathway. ATP yield of anaerobic/glycolytic way is very low compared with aerobic way. High ATP requirements are increase the affinity of glucose to the tumor tissue.

Usage of glucose derivatives for drug targeting to tumor tissue is very useful method, despite being an old idea. 2-deoxy-D-glucose (2DG) is also a glucose analogue and an inhibitor for

Received: 12 Sept. 2014, Revised 22 Sept. 2014, Accepted 24 Sept. 2014, Available Online 10 Oct. 2014

1Celal Bayar University School of Medicine, Department of Biophysics, Manisa-Turkey

2Celal Bayar University, Faculty of Art and Science, Department of Chemistry, Manisa-Turkey

3 Yüzüncü Y1l University School of Medicine, Department of Pharmacology, Van-Turkey

4Marmara University, Faculty of Technology, Department of Textile Engineering, Istanbul-Turkey

5Marmara University, Faculty of Science, Department of Organic Chemistry, Istanbul-Turkey

*Corresponding Author: Zafer Akan E-mail: zafer_akan@hotmail.com 
glucose transport and glycolytic ATP production [3]

Positron emitter radioactive ${ }^{18} \mathrm{~F}$ complexed Deoxy-D-glucose $\left({ }^{18} \mathrm{~F}\right.$-deoxy-D-glucose: $\left.{ }^{18} \mathrm{FDG}\right)$ is routinely used for the detection and staging of tumors with positron emission tomography (PET). Radioactive positron emitter ${ }^{18} \mathrm{~F}$ successfully targeted to tumor tissue by the Deoxy-D-glucose.

Boric acid $\mathrm{B}(\mathrm{OH})_{3}$ and its anion borate $\mathrm{B}(\mathrm{OH})_{4}^{-}$have solution chemistry that is quite different from most other oxyanions. Borate forms by the addition of a hydroxyl group to the trigonal planar boric acid molecule, forming a tetrahedral anion. The $\mathrm{pK}$ of this reaction is 9.2 [4]

$\mathrm{B}(\mathrm{OH})_{3}+\mathrm{OH}^{-} \leftrightarrow \mathrm{B}(\mathrm{OH})_{4}^{-} \quad$ pKa 9.2

Boric acid and borate both typically exist as monomers in solution at low concentrations (below $25 \mathrm{mM}$ ) but at higher concentrations many poly-borate polymers are known to form $[5,6]$.

Due to simple complexation properties of borate anions and easy intracellular uptake properties of 2-DG, the synthesis and complexation yield of Boric acid with Deoxy-D-Glucose $\left({ }^{10} \mathrm{~B}-\right.$ DG) were examined.

\section{Material and Methods}

\section{Complexation reaction of $\mathrm{B}(\mathrm{OH})_{3}$ and 2-DG and FT-IR/ATR measurements}

The complexation reaction of boric acid with polyhydroxyl compounds, such as tiron, has been studied, and the reaction has been well defined in previous studies [6]. In same reaction conditions were applied for $\mathrm{B}(\mathrm{OH})_{3}$ and 2-DG complexation.

A Perkin Elmer PE100 Infrared Spectrophotometer with Universal ATR Sampling Accessory was used for spectroscopic studies. All spectra were measured in the range between 1600 and $750 \mathrm{~cm}^{-1}$, at resolution of $4 \mathrm{~cm}^{-1}$ [7]. Distilled water was used as background and to clean the diamond probe between each sample. All measurements were realized at room temperature. Deionized water prepared with a Milli-Q SP system (Millipore).

0.1 M Boric acid $\left(\mathrm{B}(\mathrm{OH})_{3}\right.$; SigmaAldrich, B6768) and 0.5 M Tiron (4,5-Dihydroxy1,3-benzenedisulfonic acid disodium salt, SigmaAldrich, D7389) solutions were prepared with the same volume of deionised water and incubated for 1 hour at $\mathrm{pH}: 3$ and $50^{\circ} \mathrm{C}$.

0.1 M Boric acid $\left(\mathrm{B}(\mathrm{OH})_{3}\right.$; SigmaAldrich, B6768) and 0.5 M Deoxy-D-glucose (2-
DG: Sigma-Aldrich, D8375) solutions were prepared with the same volumes of deionized water and incubated for 1 hour at $\mathrm{pH}: 3$ and $50^{\circ} \mathrm{C}$.

Both solutions were then mixed in the same tube and incubated for 1 hour at $\mathrm{pH}: 3$. The $\mathrm{pH}$ was gradually increased from $\mathrm{pH}: 3$ to $\mathrm{pH}: 7$ and stabilized at physiologic pH:7.4. FTIR-ATR analysis were done for only $\mathrm{B}(\mathrm{OH})_{3}$, only Tiron, only DG and complexed B-Tiron and B-DG. Complexation between boric acid and the 2-DG may be expressed as eqn.

$\mathrm{B}(\mathrm{OH})_{3}+\mathrm{H}_{2} \mathrm{O} \leftrightarrow \mathrm{B}(\mathrm{OH})_{4}{ }^{-}+\mathrm{H}^{+} \mathrm{Ka}=\left[\mathrm{B}(\mathrm{OH})_{4}{ }^{-}\right]\left[\mathrm{H}^{+}\right] /\left[\mathrm{B}(\mathrm{OH})_{3}\right]$ $\mathrm{B}(\mathrm{OH})_{4}{ }^{-}+\mathrm{DG} \leftrightarrow \mathrm{B}-\mathrm{DG}+\mathrm{H}^{+} \mathrm{Ka}=\left[\mathrm{B}(\mathrm{OH})_{4}{ }^{-}\right][\mathrm{DG}] /[\mathrm{B}-\mathrm{DG}]$

\section{HPLC studies}

The following quality control studies were done to confirm Boric acid, 2-Deoxy-D-glucose and Borono-2-Deoxy-D-glucose. Table 1 shows chromatographic conditions used analytical experiments in HPLC. A low- pressure gradient HPLC system (LC-10ATvp quaternary pump and SPD-10A/V UV detector and a syringe injector equipped with a $1 \mathrm{ml}$ loop and $7-\mu \mathrm{m}$ RP-C-18 column 250 x $4.6 \mathrm{~mm}$ I.D. (inner diameter), Macherey-Nagel), was used for analytical experiments.

Table 1. Chromatographic conditions used analytical experiments in HPLC

Column in analytical exp.: $\quad$ RP-C18(250x4.6mm)

Flow speed in analytical exp.: $\quad 0.7 \mathrm{~mL} / \mathrm{min}$

Wave length: $\quad 240 \mathrm{~nm}$

Temperature: $\quad 30{ }^{\circ} \mathrm{C}$

Pressure: $\quad 76$ bar

Mobile phase in analytical exp.: $\quad 18 \mathrm{mM} \mathrm{NaOH}$

\section{LC-MS}

Liquid chromatography mass spectrometry (LC-MS) chromatograms were taken using a HCTultra LC-MS instrument. Chromatographic conditions used in this study were given in Table 2. The parameters were optimized and set as followed. Ion source Type ESI pos and ESI neg, Mass Range Mode Ultra Scan $(26000 \mathrm{~m} / \mathrm{z} / \mathrm{s})$, Column No column, direct infussion, Capillary pos $-4000 \mathrm{~V}$ and neg $+4000 \mathrm{~V}$, Drying gas tempreture $300{ }^{\circ} \mathrm{C}$, Drying gas pressure 5 psi, Nebulizing gas pressure $10 \mathrm{psi}$. 
Table 2. Chromatographic conditions for LC-MS experiments

Ion source type:

Mass range mode:

Column:

Capillary:

Drying gas tempreture:

Drying gas pressure:

Nebulizing gas pressure:
ESI pos and ESI neg

Ultra Scan $(26000 \mathrm{~m} / \mathrm{z} / \mathrm{s})$

No column direct infussion

pos $-4000 \mathrm{~V}$ and neg $+4000 \mathrm{~V}$

$300{ }^{\circ} \mathrm{C}$

5 psi

$10 \mathrm{psi}$

\section{Results}

\section{Complexation reaction of $\mathrm{B}(\mathrm{OH})_{3}$ and 2-DG}

FT-IR/ATR results of ${ }^{10} \mathrm{~B}$-Tiron and ${ }^{10} \mathrm{~B}$ DG (Fig. 1) have similar peak shifts which indicate complexation due to literature results (Fig. 2, 3), [7]. The IR spectra of these solutions of $\mathrm{B}(\mathrm{OH})_{3}, 2-$ deoxy glucose (2-DG) and ${ }^{10} \mathrm{~B}-\mathrm{DG}$ showed that formation bonding between ${ }^{10} \mathrm{~B}$ and 2-DG by the disappearance of asymmetric stretching of $\mathrm{B}(\mathrm{OH})_{3}$ at $1413 \mathrm{~cm}^{-1}$ and decreasing peaks intensity of 2 DG solution at $1264 \mathrm{~cm}^{-1}(\mathrm{O}-\mathrm{H}$ blending of deoxyglucose) and $1067 \mathrm{~cm}^{-1}, 1029 \mathrm{~cm}^{-1}$ and $1015 \mathrm{~cm}^{-1}$ (C-O stretching of deoxyglucose).

Figure 1. Chemical synthesis of Borono-Deoxy-D-glucose

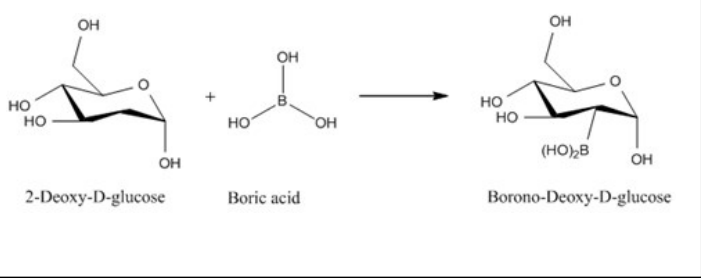

Table 3. LC-MS/MS Spectrum (m/z) Values for Borono-2Deoxy-D-glucose Compounds and Some Different Fragments and Proposed Structures of Selected Fragments

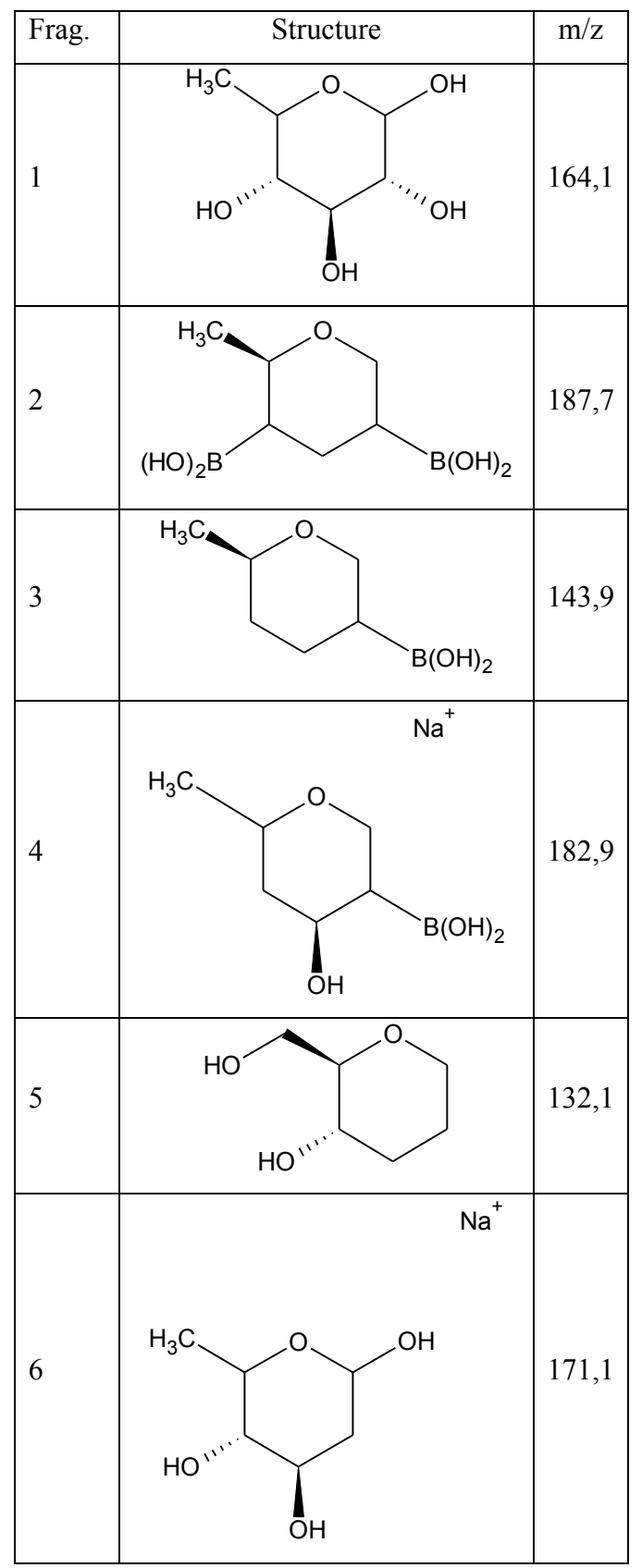


Figure 2. Complexation of $\mathrm{B}(\mathrm{OH})_{3}$-Tiron FTIR-ATR

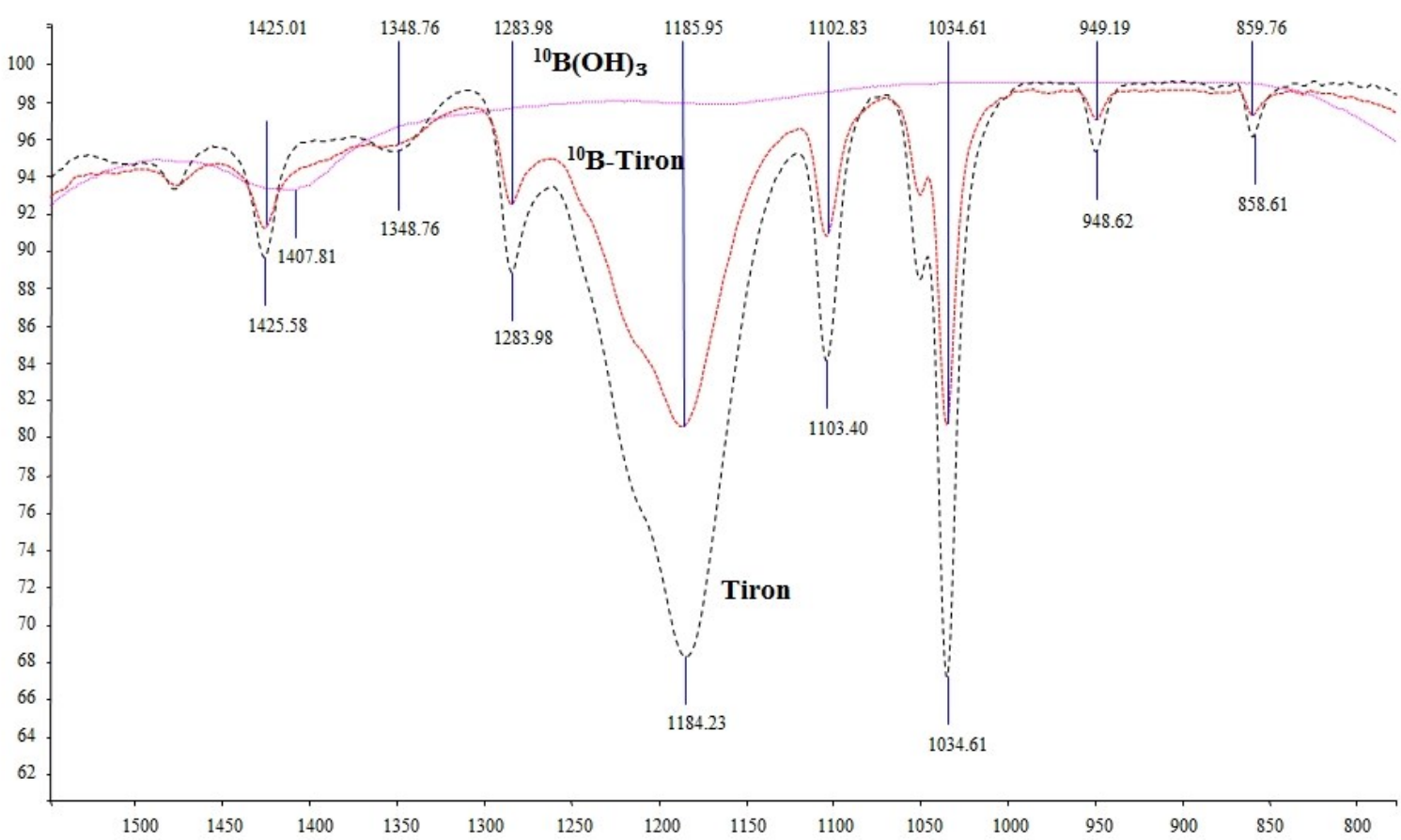

Figure 3. Complexation of $\mathrm{B}(\mathrm{OH})$-2DG FTIR-ATR

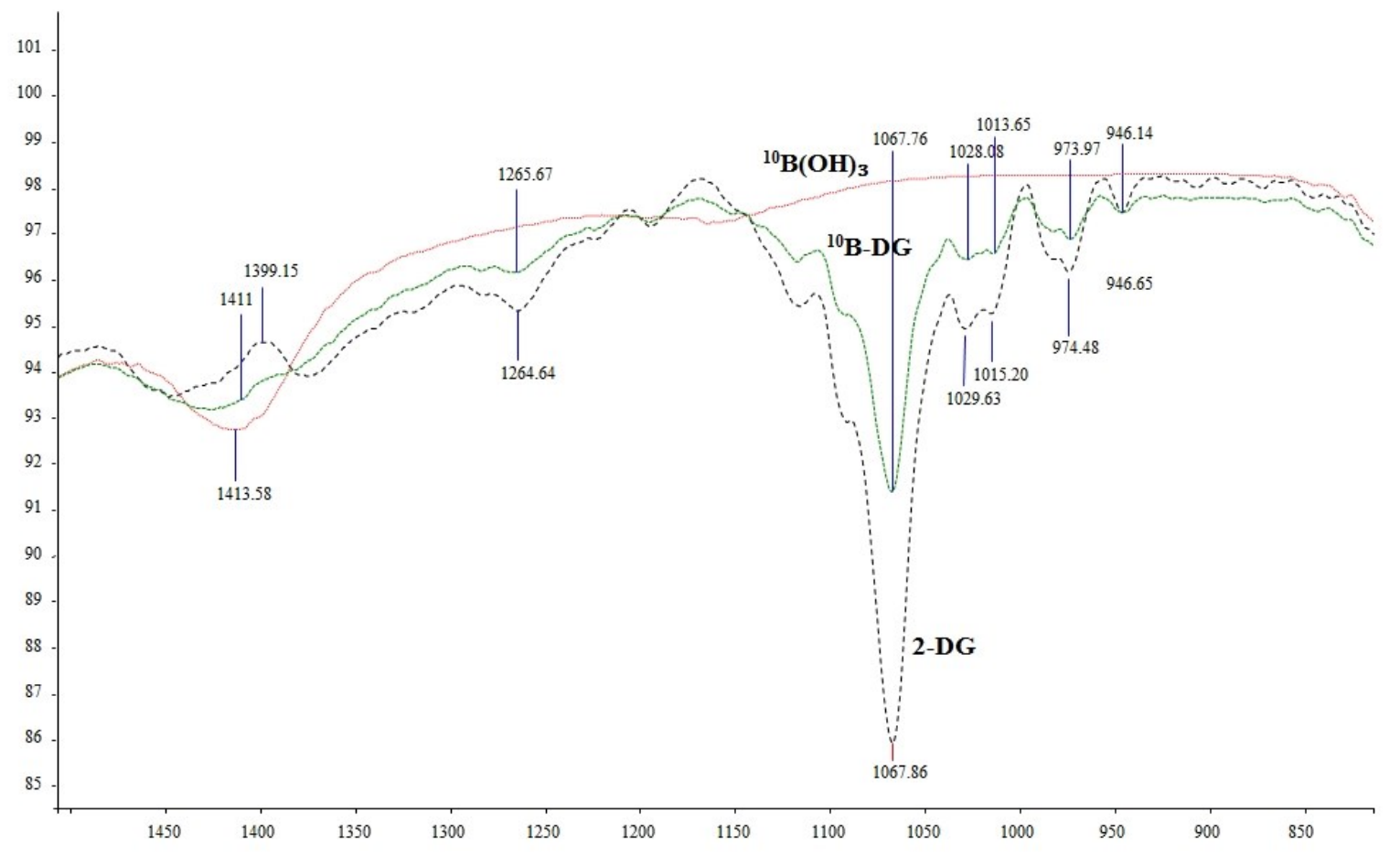

Shao and coworkers have shown that Boric acid - Tiron (1,2-dihydroxybenzene-3,5-disulfonic acid disodium salt monohydrate) complex characterization by ${ }^{11} \mathrm{~B}$ NMR spectra and proved forming complex between Boric acid and Tiron [6] In this work Boric acid-Tiron complex were investigated by IR Spectra. The IR spectra of solutions Tiron, B, B-Tiron were taken. The IR spectra (Figure 2) showed that the disappearance of asymmetric stretching of $\mathrm{B}(\mathrm{OH})_{3}$ at $1407 \mathrm{~cm}^{-1}$ like in Figure 3. This indicates that boric acid form complex with deoxyglucose like Tiron. 


\section{Results of HPLC and LC-MS studies}

HPLC chromatograms confirmed that Borono-2-Deoxy-D-glucose synthesized with $80 \%$ yield. Three peaks were detected for Borono-2Deoxy-D-glucose HPLC analyses, the retention times of related compounds were different from each other as is seen in Figure 4 and Figure 5. Retention times are 3.68, 4.18 and $4.87 \mathrm{~min}$ for Boric acid, 2-Deoxy-D-glucose and Borono-2Deoxy-D-glucose, respectively.

LC-MS spectrum $(\mathrm{m} / \mathrm{z})$ values for Borono2-Deoxy-D-glucose compounds and some different fragments and proposed structures of selected fragments $(\mathrm{m} / \mathrm{z})$ values are 162,1 : $187: 143,9$ : $182,9: 132,1: 169,1$.

\section{Discussion}

Most cancer cells exhibit increased glycolysis and use this metabolic pathway (anaerobic pathway) for generation of ATP as a main source of their energy supply because of delayed angiogenesis. This phenomenon is known as the Warburg effect and is considered as one of the most fundamental metabolic alterations during malignant transformation. Although delayed angiogenesis seen as a chance to delay for metastases, makes malignancies chemotherapyresistant. Beside of chemotherapeutic resistant, oxygen-free environment due to malignant transformation makes cancer cells resistant to radiotherapy too [8] Importantly, the increased dependence of cancer cells on glycolytic pathway for ATP generation provides a biochemical basis for the design of therapeutic strategies to preferentially kill cancer cells by pharmacological inhibition of glycolysis. Several small molecules have emerged that exhibit promising anticancer activity in vitro and in vivo, as single agent or in combination with other therapeutic modalities [9]. 2-Deoxy-D-glucose is a glucose molecule which has the 2-hydroxyl group replaced by hydrogen, so that it cannot undergo further glycolysis. As such, it acts to competitively inhibit the production of glucose-6- $\mathrm{PO}_{4}$ from glucose at the phosphoglucoisomerase level [10].

2-DG is easily uptaken by the glucose transporters of the cell. Therefore, cells with higher glucose uptake, for example tumor cells, have also a higher uptake of 2-DG.

Inhibition of glycolysis by the small glycolysis inhibitors (GI) brought up to the use of combine usage of glycolysis inhibitors with chemotherapeutics in the treatment of malignant tumors therefore affectivity research of 2-DG Chemotherapeutic combine treatments were recently started in clinical trials [11].

Due to higher glucose uptake of tumor cells, radiolabelled 2-DG $\left({ }^{18} \mathrm{~F}-\mathrm{DG}\right)$ is also routinely using for tumor imaging and staging with positron emitting tomography since 1990's (PET) [12].

Even if alternative reactions can be used for 2-DG and boric acid complexation which enrolled in the study as alternative boron carrier; 2-DG and Boric Acid thought to be complexed rapidly and easily via low-high $\mathrm{pH}$ reactions due to poly-hydroxyl components of two molecules. Low-high $\mathrm{pH}$ reactions have been recommended in the literature for similar boric acid reactions [6].

If compare with low-high $\mathrm{pH}$ complexation reaction results, yield is very low for other reactions and reaction time is not reasonable. For example, nucleophilic substitution reaction is more widely used for $18 \mathrm{~F}, 2-\mathrm{DG}$ complexation reaction and electrophilic fluorination reaction has an important place in the synthesis of 18F-FDG. Synthesis of $18 \mathrm{~F}-\mathrm{FDG}$ in radio-fluorination reactions, triflates produces a moderate consistent yield at about 50 to $60 \%$ [13].

Boric acid reacts with polyhydroxyl compounds as a Lewis acid to form complex in aqueous solution. 2-Deoxy-D-glucose has the 2hydroxyl group therefore simple $\mathrm{pH}$ complexation reaction was designed as defined in previous studies [6]. 
Figure 4. HPLC chromatograms of 2-Deoxy-D-glucose and Borono-2-Deoxy-D-glucose (first pink peak belongs to 2-Deoxy-Dglucose, Rt (Retention time):4.18 min and the second black peak is Borono-2-Deoxy-D-glucose, Rt (Retention time): $4.87 \mathrm{~min}$ )

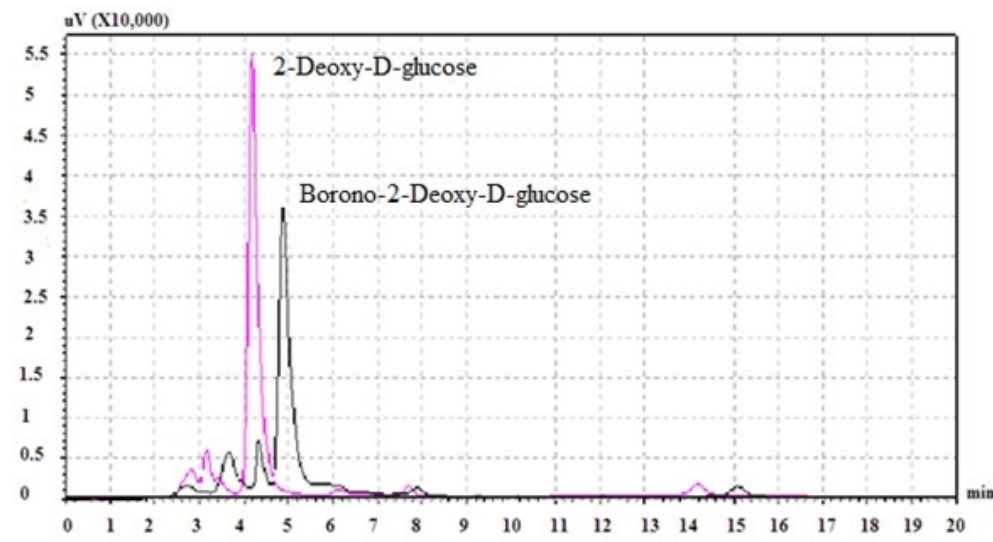

Figure 5. HPLC chromatograms of Boric acid $\mathrm{B}(\mathrm{OH})_{3}$, Rt (Retention time): 3,68 min

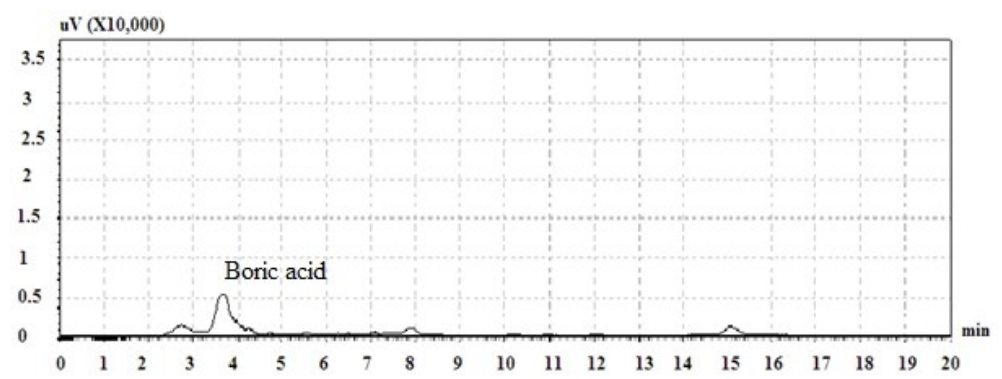

We have accomplished the effective and simple synthesis of $((2 R)-4,5,6$-trihydroxy-2(hydroxymethyl)tetrahydro-2H-pyran-3-yl)boronic acid by the low-high $\mathrm{pH}$ reaction in high yields and short time. This method also could be applied to synthesis of (6-fluoro-2,4,5-trihidroxyoxan-3-yl) boronic acid. Complexation of $\mathrm{B}(\mathrm{OH})_{3}$ with 2-DG was observed with FT-IR/ATR also proved with LC-MS and yield of complexation was measured by the HPLC. Peak areas of HPLC chromatograms confirmed that Borono-2-Deoxy-D-glucose synthesized with a higher consistent yield at about $80 \%$.

In this work, due to successfully carrier properties, 2-DG thought to be alternative Boron carriers for BNCT application and boron $\left({ }^{10} \mathrm{~B}\right)$ successfully complexed with 2-DG.

\section{Acknowledgments}

This research was supported by grants from the Turkey National Boron Research Institute (BOREN-2011-Ç0289). Patent rights to its innovative production process for BNCT are protected by the BOREN. The authors thanks to Dr. Serap Teksöz, Dr. Çiğdem Acar İçhedef for their technical assistance during the HPLC studies. There is no conflict of interest between researchers.

\section{References}

1. van Vulpen M, van den Bosch MA, Verkooijen HM, Lagendijk JJ. [Developments in radiotherapy: imageguided and minimally invasive]. Nederlands tijdschrift voor geneeskunde. 2013;157(26):A5857.

2. Wu G, Barth RF, Yang W, Lee RJ, Tjarks W, Backer MV, et al. Boron containing macromolecules and nanovehicles as delivery agents for neutron capture therapy. Anticancer agents in medicinal chemistry. 2006;6(2):167-84.

3. Dwarakanath BS. Cytotoxicity, radiosensitization, and chemosensitization of tumor cells by 2-deoxy-D-glucose in vitro. Journal of cancer research and therapeutics. 2009;5 Suppl 1:S27-31.

4. Peak D, Luther GW, Sparks DL. Boric acid and borate adsorption mechanisms on amorphous iron oxides: An in situ ATR-FTIR spectroscopic study. Geochimica et Cosmochimica Acta. 2003 67:14,2551-2560.

5. Cotton FA, Wilkinson G. Advanced Inorganic Chemistry. New York, Wiley. 1980.

6. Shao C, Matsuoka S, Miyazaki Y. Studies on the Complexation of Boric Acid with Polyhydroxyl Compounds. Analytical Sciences, vol:17, supplement. 2001.

7. Girard JM, Deschenes JS, Tremblay R, Gagnon J. FTIR/ATR univariate and multivariate calibration models for in situ monitoring of sugars in complex microalgal culture media. Bioresource technology. 2013;144:664-8. 
8. Cohen-Jonathan Moyal E. [Angiogenic inhibitors and radiotherapy: from the concept to the clinical trial]. Cancer radiotherapie : journal de la Societe francaise de radiotherapie oncologique. 2009;13:562-7.

9. Pelicano H, Martin DS, Xu RH, Huang P. Glycolysis inhibition for anticancer treatment. Oncogene. 2006;25(34):4633-46.

10. Wick AN, Drury DR, Nakada HI, Wolfe JB. Localization of the primary metabolic block produced by 2deoxyglucose. The Journal of biological chemistry. 1957;224(2):963-9
11. Raez LE, Papadopoulos K, Ricart AD, Chiorean EG, Dipaola RS, Stein MN, et al. A phase I dose-escalation trial of 2-deoxy-D-glucose alone or combined with docetaxel in patients with advanced solid tumors. Cancer chemotherapy and pharmacology. 2013;71(2):523-30.

12. Coleman RE. Clinical PET in Oncology. Clinical positron imaging : official journal of the Institute for Clinical PET. $1998 ; 1(1): 15-30$

13. Yu S. Review of F-FDG Synthesis and Quality Control. Biomedical imaging and intervention journal. 2006;2(4):e57

Copyright (C) 2014 The Author(s); This is an open-access article distributed under the terms of the Creative Commons Attribution License (http://creativecommons.org/licenses/by/4.0), which permits unrestricted use, distribution, and reproduction in any medium, provided the original work is properlv cited. 